\title{
Titania-Silica Composites: A Review on the Photocatalytic Activity and Synthesis Methods
}

\author{
Yuri Hendrix, Alberto Lazaro, Qingliang Yu, Jos Brouwers \\ Department of the Built Environment, Eindhoven University of Technology, Eindhoven, The Netherlands \\ Email: Q.Yu@bwk.tue.nl
}

Received 9 November 2015; accepted 18 December 2015; published 21 December 2015

Copyright (C) 2015 by authors and Scientific Research Publishing Inc.

This work is licensed under the Creative Commons Attribution International License (CC BY). http://creativecommons.org/licenses/by/4.0/

(c) $\underset{\mathrm{EY}}{\mathrm{B}}$ Open Access

\begin{abstract}
The photocatalyic activity of titania is a very promising mechanism that has many possible applications like purification of air and water [1]-[4]. To make it even more attractive, titania can be combined with silica to increase the photocatalytic efficiency and durability of the photocatalytic material, while lowering the production costs [1]. In this article, relevant literature is reviewed to obtain an overview about the chemistry and physics behind some of the different parameters that lead to cost-effective photocatalytic titania-silica composites. The first part of this review deals with the mechanisms involved in the photocatalytic activity, then the chemistry behind certain methods for the synthesis of the titania-silica composites is discussed, and in the last and third part of this review, the influence of silica supports on titania is discussed. These three sections represent three different fields of research that are combined in this review to obtain better insights on the photocatalytic titania-silica composites. While many research subjects in these fields have been well known for some time now, some subjects are only more recently resolved and some subjects are still under discussion (e.g. the cause for the increased hydrophilic surface of titania after illumination). This article aims to review the most important literature to give an overview of the current situation of the fundamentals of photocatalysis and synthesis of the cost-effective photocatalyic composites. It is found that the most cost-effective photocatalytic titania-silica composites are the ones that have a thin anatase layer coated on silica with a large specific surface area, and are prepared with the precipitation or sol-gel methods.
\end{abstract}

\section{Keywords}

Photocatalysis, Photocatalytic $\mathrm{TiO}_{2}$, Titania-Silica Composites, Low Cost Synthesis 


\section{Introduction}

Composites made out of silica and titania can have the photocatalytic properties from titania, the high stability from silica and extra properties coming from chemical bonds between the two materials [1]. Titania is photocatalytic because it is able to absorb energy from light, and then use that energy to catalyze the degradation of organic molecules and the oxidation of some inorganic pollutants like nitrogen oxides $\left(\mathrm{NO}_{\mathrm{x}}\right)$ [1]-[12]. As the photocatalytic activity takes place only on the exposed surface area of titania, the amount of titania needed for the same photocatalytic efficiency can be reduced enormously by coating a thin layer of titania on silica [5] [13]-[42]. As the production of silica can be cheaper than that of titania, the costs of the photocatalyic material can then be significantly reduced. In addition to lower production costs, the durability increases as silica has a higher mechanical and thermal stability than titania. So when the composites are used instead of pure titania, the photocatalytic material can be used for a longer time with high photocatalytic efficiencies. In addition, because of the enhanced thermal stability, the photocatalytic material can be used in applications that require higher preparation temperatures. In addition to the lower costs and increased durability, the photocatalytic efficiency of the material can be increased with the addition of silica because silica can have a large specific surface area and is able to adsorb some pollutants and intermediates for a longer time than pure titania.

One promising application of the photocatalytic materials is the degradation of pollutants. The main reasons why using photocatalytic materials for air purification is promising include: lower costs of materials and energy needed than the other current purification methods, the ability of many photocatalytic materials to oxidize pollutants even if they are present in low concentrations, and the fact that the pollutants do not have to be stored but are converted into less harmful side-products (e.g. $\mathrm{CO}_{2}$ from organic molecules and $\mathrm{NO}_{3}{ }^{-}$from $\mathrm{NO}_{\mathrm{x}}$ after a complete photocatalytic oxidation (PCO)). The photocatalytic titania has been, and is being used in many other applications as well, including: photoelectrolysis of water, medical applications (where titania works as a disinfectant by destroying bacteria and viruses), municipal and industrial wastewater treatment, self-cleaning glass with anti-fogging abilities, and even in textiles that are self-cleaning.

A good method to have air purification is by the incorporation of photocatalytic material in building materials (including: concrete, wallpaper, gypsum and paint [2]-[4] [8]-[10] [43]-[51]), due to the large illuminated surfaces areas that many building materials have. Investigations into the photocatalytic building materials showed that the concentration of pollutants close to photocatalytic building materials indeed significantly decreased. Since large areas of building materials are often illuminated anyway with sun-light or indoor light and because these building materials become self-cleaning, the maintenance costs of these materials can be very low. Because of the large illuminated area and low maintenance cost, the potential of the photocatalytic building material for air purification is very promising.

However, in most of the research field of the applications of photocatalytic materials, only pure and doped titania are mentioned and not the titania-silica composites despite the large benefits these composites can have (e.g. lower costs, higher durability). An important reason for this absence of composites can be the complexity of the research field of the titania-silica composites. For the synthesis of the titania-silica composites alone, there are many different methods, each with their own parameters that can be changed in multiple ways. As many studies on the titania-silica composites have been done with different goals in mind, many different kinds of titania-silica composites have been produced [1] [5] [13]-[42] [52]-[84], from which some are either not suitable for photocatalysis or have a very expensive production method. Since the photocatalytic activity of titania alone is already a complex system [3] [4] [6] [11] [85]-[89], it can be understandable that adding more complexity to the system (for example, with silica) is not desirable. This review is written in order to provide insight on the low cost synthesis of titania-silica composites, and how each different parameter can be tuned to produce highly efficient photocatalytic material to show how the composites can be an attractive alternative to the titania for photocatalytic applications.

\section{Photocatalytic Titania}

\subsection{Mechanism of Photocatalysis}

The process of photocatalysis in titania starts when a photon is absorbed by an electron in the valance band of titania [3] [4] [6] [11] [85]-[89]. This electron is then excited to the conduction band, and by doing so, leaves a hole behind in the valance band (reaction 1). The valance and conduction bands of titania have the right energy 
levels for many important redox reactions. After the excitation of electrons, holes in the valance band have a redox potential of $+2.53 \mathrm{~V}$, which is enough for the oxidation of hydroxyl ions into $\mathrm{OH}^{*}$ (see reaction 2) or the oxidation of adsorbed organic molecules groups. The largest source of hydroxyl ions comes from the dissociation of water (see reaction 3). The redox potential of electrons in the conduction band is $-0.52 \mathrm{~V}$, which is strong enough to reduce oxygen to superoxide (see reaction 4). It is also possible that the excited electrons and holes will react with different adsorbed species depending on the environment. For example, if there is a high amount of adsorbed water, it is possible that more radical hydroxyls will form through the reaction of hydrogen peroxide as shown in reaction 5 and 6.

$$
\begin{array}{r}
\mathrm{TiO}_{2}+\text { light } \rightarrow \mathrm{TiO}_{2}+\mathrm{e}^{-}+\mathrm{h}^{+} \\
\mathrm{OH}^{-}+\mathrm{h}^{+} \rightarrow \mathrm{OH}^{\cdot} \\
\mathrm{H}_{2} \mathrm{O} \rightleftarrows \mathrm{OH}^{-}+\mathrm{H}^{+} \\
\mathrm{O}_{2}+\mathrm{e}^{-} \rightarrow \mathrm{O}_{2}^{-} \\
\mathrm{O}_{2}+2 \mathrm{H}_{2} \mathrm{O}+2 \mathrm{e}^{-} \rightarrow 2 \mathrm{H}_{2} \mathrm{O}_{2} \\
\mathrm{H}_{2} \mathrm{O}_{2}+\mathrm{e}^{-} \rightarrow \mathrm{OH}^{-}+\mathrm{OH}^{-}
\end{array}
$$

where $\mathrm{e}^{-}$is an excited electron in the conduction band, $\mathrm{h}^{+}$is a hole in the valance band, $\mathrm{OH}^{*}$ is a radical hydroxyl and $\mathrm{O}_{2}^{-}$is a superoxide. Radical hydroxyls and superoxides are strong oxidants that can react with certain inorganic pollutants like $\mathrm{NO}_{\mathrm{x}}$ and many organic molecules. In Figure 1, a schematic view is given for the photocatalytic mechanism.

An important property of titania, which influences the photocatalytic efficiency, is the amount of hydroxyl groups in its environment. In turn, the amount of hydroxyl groups is determined by the humidity in air, or the amount of water and its $\mathrm{pH}$ in liquids. This amount will determine how many hydroxyl groups will be chemically bonded to the surface of the titania. Bonded hydroxyl groups can either react with holes themselves and form radicals, or adsorb other hydroxyl groups and water molecules which can subsequently react with the holes and excited electrons [90] [91]. The photocatalytic activity in air can thus be higher with a higher humidity. However, it is also possible that a very high humidity will lower the photocatalytic activity by taking up more adsorption sides on the surface. For example, the photocatalytic oxidation of $\mathrm{NO}_{\mathrm{x}}$ depends on the adsorption to titania and is thus lower with a very high humidity.

\subsection{Oxygen Vacancies, Hydrophilicity and Self-Cleaning Surfaces}

By reacting $\mathrm{Ti}^{4+}$ and $\mathrm{O}^{2-}$ into $\mathrm{Ti}^{3+}$ and $\mathrm{O}^{-}$, excited electrons and holes can remain at the surface longer if there are no adsorbed species they can react with directly [3]. Because the difference in charge between titanium and oxygen atoms is then reduced, the oxygen atoms are much less stable and can, with relatively little energy, leave the crystal forming oxygen vacancies. These oxygen vacancies are important in titania for different mechanisms. For example, around an oxygen vacancy there is an excess of electrons, making titania a n-type semiconductor,
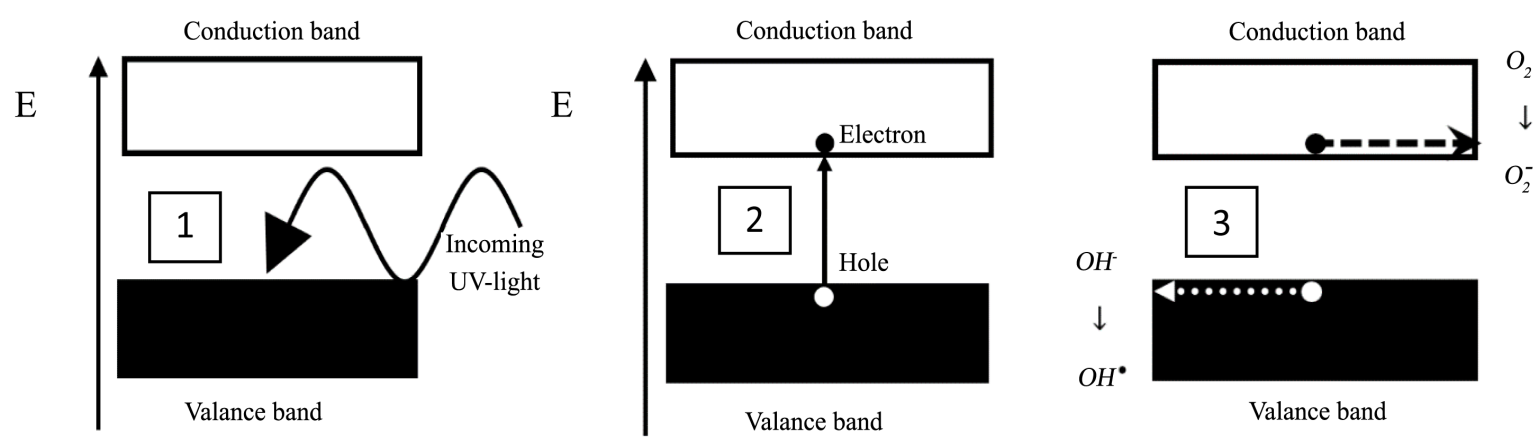

Figure 1. Schematic drawing of the photocatalytic activity of titania. 1: The absorption of a photon; 2: The excitation of an electron to the conduction band; 3: The transport of the electron and hole from the initial point to reach the surface of titania where the electron and hole can react with an adsorbed molecule. 
which has a higher conductivity than when titania is an intrinsic semiconductor.

Another reason why oxygen vacancies are important is because the surface of titania becomes more hydrophilic when water molecules occupy these oxygen vacancies. After a water molecule occupies the vacancy, one hydrogen atom of the water molecule can react with a neighboring oxygen atom forming two hydroxyl groups [3]. The increase in hydroxyl groups can lead to an increase in photocatalytic efficiency and to an increase in hydrophilicity of the surface. This increase in hydrophilicity, was first reported by Wang et al. [92] in 1997 with a titania coating on glass. By illuminating the coated glass with UV-light, the glass became transparent since the water fog that was present on the glass, defogged as the contact angle between the water droplets and the glass decreased to zero. They also showed that after keeping the hydrophilic surface away from any light source for some days, the glass became more hydrophobic, which means that the formation of a hydrophilic surface is a reversible process. However, it has been reported that oxygen vacancies are not solely responsible for the hydrophilicity, as some studies showed that hydrophilicity was independent in some cases on the number of oxygen vacancies [93] [94]. While it is possible that the degradation of organic materials on the surface can also play a role on the hydrophilicity increase, it nevertheless has been shown not to be a determining factor [95].

The hydrophilicity and the degradation of organic materials on the surface of titania are two reasons why titania can be used for self-cleaning applications [3]. The degradation of organic materials through photocatalytic oxidation prevents organic substances to accumulate on the surface and can prevent the growth of bacteria and fungi. The hydrophilicity of the surface increases the water adsorption so that it can replace other adsorbed species and it lowers the energy required for water to slide over the surface so that contaminants can be washed off more easily.

\subsection{Effect of Different Crystal Forms of Titania on the Photocatalytic Efficiency}

Titania has several forms, but the two main crystal structures that most researchers focus on are rutile and anatase [3]. These two crystal forms are both tetragonal structures in which titanium atoms are 6-coordinated in an octahedral formation. The band gap of rutile is $3.0 \mathrm{eV}$ and the band gap of anatase is $3.2 \mathrm{eV}$. For rutile and anatase to become photocatalytically active, they need to absorb electromagnetic radiation with wavelengths smaller than $413 \mathrm{~nm}$ and $387 \mathrm{~nm}$ respectively. While rutile is thus able to absorb more light in the visible range, anatase is more photocatalytically active. Luttrell et al. [96] showed this higher photocatalytic efficiency by studying the difference in PCO efficiencies of anatase and rutile thin films of different sizes for the PCO of methyl orange. They showed that for films thinner than $2.5 \mathrm{~nm}$ the difference was not significant between the two forms, but for thicker films, the anatase thin film had a higher efficiency. They measured that the maximum thickness, where the photocatalytic efficiency increases with increasing size, is $2.5 \mathrm{~nm}$ for rutile and $5 \mathrm{~nm}$ for anatase. Thus, from this study it can be concluded that excited electrons and holes in anatase can travel farther than in rutile so that more electrons and holes can reach the surface. The ability of exited electrons and holes to travel longer distances in anatase was contributed to a longer lifetime and higher conductivity [96]-[98].

An important reason why excited electrons and holes have a longer lifetime and higher conductivity in anatase is because of the differences between the oxygen vacancies that form in anatase and rutile. Oxygen vacancies cause extra energy levels within the band gap. Calculations done by Mattioli et al. [97] showed that oxygen vacancies in an anatase crystal can cause both shallow delocalized energy levels and deep localized energy levels in the band gap, while in rutile only deep localized levels can form. Since anatase has also shallow delocalized energy levels in its band gap, it has a higher conductivity and the excited electrons and holes have longer lifetimes than in rutile as they are less trapped in the deep localized energy levels where the chance of recombination is higher.

While anatase has a high photocatalytic efficiency, amorphous titania has the lowest efficiency [99]. The main reason for this lower efficiency is because, in amorphous titania, there are many spots where recombination of the electron-hole pair can happen. The recombination through defects is the most common way electrons and holes are lost. Thus, amorphous titania has a much higher recombination capacity. In addition, conductivity in amorphous materials is very low since energy levels in amorphous materials are much more localized. The high recombination rate and low conductivity means that only electrons which are excited directly at the surface play a part in the photocatalytic activity in amorphous titania.

Some researchers have measured higher PCO efficiencies in titania that contains both rutile and anatase than in titania with only anatase. Degussa P25 nanoparticles, which are commercial titania nanoparticles made out of 
around $80 \%$ anatase and 20\% rutile, are well known for their high photocatalytic activity [100] and are often used as a reference material. The conduction band of rutile has been measured to start at a higher energy level than that of anatase even though its band gap is smaller, which is why titania with both crystal forms can have a higher photocatalytic efficiency [101]. Since electrons always go to a lower energy state if possible, excited electrons in rutile will go to the conduction band of anatase. As electron holes can be viewed as opposite electrons, electron holes in anatase will flow to the valance band of rutile because its top lies above the energy level of the valance band from anatase. Because holes move from anatase to rutile and excited electrons from rutile to anatase, the recombination chance is reduced and a difference in electron density is produced at the interface between the two forms, causing an increase in conductivity and lifetimes for the electrons and holes, resulting in a higher photocatalytic efficiency.

\section{Titania-Silica Composite Synthesis}

\subsection{Silica Sources}

Many different types of silica from different sources can be applied as a support for titania including: fumed silica, precipitation silica from alkali silicates, silica produced with the Stöber method, zeolites, clays, glass, silica from the dissolution of silica minerals and more [1] [5] [13]-[42] [52]-[84] [102]-[107]. Fumed silica is formed at high temperatures where silica compounds, like chlorosilanes, are transformed into silica [108] [109]. Silica from alkali silicates is formed by neutralization of the alkali solutions so that the silicate polymerizes to silica and precipitates from the solution. In both fumed silica and precipitated silica, amorphous aggregates are formed. These aggregates can have very large specific surface areas but also have complex undefined structures. Another silica which is often used because of the more defined structure, is silica made with a sol-gel method. The Stöber method [110] is the best known example of a sol-gel method for producing silica. During this method, Tetraethyl orthosilicate (TEOS) is slowly added to a solution of ethanol, water and ammonia. Depending on the composition of the solution, silica colloids of varies sizes and shapes can be formed. The advantage of this silica is that the resulting shape and size of the silica can be well controlled. However, the disadvantage is that this silica has a smaller specific surface area than fumed and precipitated silica. For both well-defined shapes and high specific surface areas, researchers have also used zeolites as support. However compared to the other mentioned supports, the zeolites are more expensive. For very low production costs and a high specific surface area, silica made during the dissolution of olivine has a great potential [111]-[114] but is still in its developing stage.

\subsection{Titania-Silica Chemistry}

The reaction of titania precursors with silica happens either directly with silanols or indirectly through hydrolysis into titania monomers $\left(\mathrm{Ti}(\mathrm{OH})_{4}\right)$ first and subsequently by condensation with silanols [1] [5] [13]-[42] [52][84] [109] [115]. Either way, the titania will form bonds with the silica through reaction 7.

$$
\equiv \mathrm{Si}-\mathrm{OH}+\mathrm{R}-\mathrm{Ti} \equiv \rightarrow \equiv \mathrm{Si}-\mathrm{O}-\mathrm{Ti} \equiv+\mathrm{HR}
$$

where $\mathrm{R}$ is a side group of a titania precursor or a hydroxyl group of a titania monomer. The Si-O-Ti bond can be measured by using techniques like infra-red/Raman spectrometry and X-ray photoelectron spectroscopy [14]-[16] [32]-[34] [52] [56]-[60]. This condensation reaction between the titania precursor and the silica surface depends mostly on the hydroxyl groups of the silica [16] [56] [59] [63] [66] [67] since the rest of the silica is very inert. In turn, the amount of hydroxyl groups on the silica is dependent on the temperature during the pretreatment, the method used, and the amount of water and its pH used [67] [109]. For example, if the silica undergoes pre-heating temperatures higher than $800^{\circ} \mathrm{C}$ and no water is used during the synthesis, there will be only a low amount of hydroxyl groups on the silica surface left so that only a few titanium atoms can be found on the silica after the reaction [67]. On the other hand, if lower temperatures are used, the density of hydroxyl groups will be high enough on the silica surface that hydrogen bonds between silanols can form. Titania precursors react more with these hydrogen bonded silanols than isolated silanols [66] [67]. These silanols are close enough to each other that a titania precursor can react with multiple hydroxyl groups, making the reaction of hydrogen bonded silanols favorable over the reaction of isolated silanol.

When water is used during the synthesis method of the titania-silica composites, the titania precursor undergoes hydrolysis first. During the hydrolysis, the side groups of the precursor are replaced by hydroxyl groups [116]-[119]. After a full hydrolysis at a neutral $\mathrm{pH}, \mathrm{Ti}(\mathrm{OH})_{4}$ is the most common product, as titanium has four 
valance electrons. Below a pH of 4, the ions $\operatorname{Ti}(\mathrm{OH})_{3}^{+}$and $\mathrm{Ti}(\mathrm{OH})_{2}^{2+}$ can also be formed [116] [117]. It is also possible that, a double bonded oxygen atom which stays bonded during the hydrolysis, forms during the reaction of the precursor so that only two hydroxyl groups can bond to the titanium. Titanium hydroxides are titania monomers that can form larger titania molecules by polymerization through condensation with other monomers if their concentration is high enough.

\subsection{Different Synthesis Methods}

There are many different methods to synthesize the titania-silica composites. An indirect way to prepare them is by adding premade titania nanoparticles to a silica support [103] [120] [121] at a pH of around 3 - 4. At that pH, the titania and silica have opposite charges so that the titania and silica will have electrical attraction. However, for more stability and a better homogenous coating, direct methods are often more favorable. The vapor-deposition methods (chemical vapor deposition (CVD) and physical vapor deposition (PVD)), for example, are such methods [5] [23]-[25] [66]-[70]. During the CVD method, the titania precursor is heated to the gas phase to react with dry silica in an inert environment and during the PVD method the titania is sputtered against a support surface for thin films. The impregnation [17]-[22] [52] [59]-[63] and the grafting [52] [64] [65] methods are also direct methods. During both these methods, the titania precursor is dissolved in an organic solvent like toluene or hexane. This solvent is then added to the silica support so that the precursor reacts with the silanols. During the grafting method, the solvent is removed through evaporation and during the impregnation method, the solvent is removed in some other way (e.g. filtration). During the vapor-deposition, the impregnation and the grafting methods, no water is used, which means that these methods do not have the option to form more than one layer of titania in one step, because no new hydroxyl groups can form on the coated titania during the reactions for further condensation. In addition, these methods are not optimal for low cost production since either very high temperatures or expensive organic solvents are required.

Methods that are more promising for low cost photocatalytic materials are the precipitation methods [13]-[16] [52]-[58] and the sol-gel methods [14] [32]-[42] [72]-[84]. These methods are capable of forming more than one monolayer titania on silica, and do not require expensive solvents. During the precipitation method, the titania precursor is dissolved in an aqueous solution with a low $\mathrm{pH}$ and low temperatures, where titania does not form. After mixing the aqueous solution containing the precursor with the silica, the solution is either neutralized with an alkaline solution and/or heated up to a specific temperature. This specific temperature depends on the $\mathrm{pH}$ and solvent used. By increasing the $\mathrm{pH}$ and/or temperature, titania slowly forms, which can be on a silica support for a coating if the hydrolysis is slow enough so that the concentration of titania monomers does not reach the critical supersaturation. Titanium chlorides $\left(\mathrm{TiCl}_{3}, \mathrm{TiCl}_{4}\right)$ and titanium oxysulfate $\left(\mathrm{TiOSO}_{4}\right)$ are the precursors, which are often used in the precipitation methods. During the sol-gel methods, titanium alkoxides (e.g. titanium isopropoxide, titanium n-butoxide) are often used. To form a titania coating, the precursor is slowly added to a silica dispersion in an organic solvent (ethanol, n-propanol) which contains a low amount of water or to which a low amount of water is added after the precursor is added.

An important parameter in the methods that involves hydrolysis is the $\mathrm{pH}$. Below pH 6, part of the $\mathrm{Ti}(\mathrm{OH})_{4} \mathrm{is}$ replaced by $\mathrm{Ti}(\mathrm{OH})_{3}^{+}$, and also by $\mathrm{Ti}(\mathrm{OH})_{2}^{2+}$ below $\mathrm{pH} 4$. With decreasing $\mathrm{pH}$, more $\mathrm{Ti}(\mathrm{OH})_{4}$ is replaced by the ions which lead to a higher solubility [116]. A higher solubility means that the equilibrium between monomers and condensed titania is then more to the side of the monomers. Thus, when a low $\mathrm{pH}$ is used, more precursor is needed for the same amount of the condensated titania, as some of the titania monomers stay dissolved [116]. Since it is mostly the removal of $\mathrm{OH}^{-}$groups that lead to the formation of ions, hydrated, amorphous and small sized titania particles are more dissolvable than crystalline titania and titania bonded to larger particles like the silica [122] [123]. The peptizing method, which is a different kind of sol-gel method, uses this constant equilibrium between titania monomers and condensated titania in an aqueous solution and the difference in dissolvability. During this method, hydrated precipitates are first formed in an aqueous solution and then slowly dissolved by reducing the $\mathrm{pH}$ to around 2 - 4. Using the Ostwald ripening process, crystalline titania nanoparticles are then formed [122] [123] or coated on a silica support [15].

Another way to use the sol-gel method for low cost photocatalytic material is by coating a support, like a glass plate, with a thin film using the dip-coating method [124]-[133]. During the dip-coating method, the support is dipped into a stable sol-gel mixture, and is then slowly pulled out of the mixture so that a thin layer of the mixture is adsorbed to the surface. During the drying, a thin titania film is then formed. Polymers (e.g. Poly 
(ethylene glycol)) can be used to obtain a higher porosity. By adding these large molecules in the sol-gel mixture, large pores are formed during the calcination step, when these molecules are removed.

Another method which is often used for the synthesis of titania-silica composites is the hydrothermal treatment [26]-[31] [71] [72]. The advantage of this method is that it can be used for both the coating step and the crystallization step (which will be discussed in 3.5). This method is done by adding a precursor, a solution containing some water and the silica (or silica source) to an autoclave. The solution is then heated up (e.g. to $200^{\circ} \mathrm{C}$ ) for both the reaction and crystallization step.

\subsection{Controlling the Hydrolysis Rate}

For a homogenous coating with the seeded-growth process, the concentration of titanium monomers should not exceed the critical supersaturation, and thus the hydrolysis rate needs to be controlled. In aqueous solutions with a neutral $\mathrm{pH}$, the hydrolysis of titania precursors happens so fast that the concentration of the monomers reaches the critical supersaturation point almost instantly, causing the titania to precipitate randomly in the solution instead of slowly forming on the silica surface.

The most important parameters on which the hydrolysis rate of titania precursors is dependent are: the $\mathrm{pH}$, temperature, concentration of the precursor and of water, and type of precursor used. For example, in an aqueous solution with a pH below 1 and a temperature below $20^{\circ} \mathrm{C}$, no titania will form [13]-[16] [52]-[58]. Having organic liquids (like n-propanol) [134] in the solvent increases the temperature and $\mathrm{pH}$ at which the titania is still soluble, because the dielectric constant of the solvent is then decreased. Having a low water content also prevents fast hydrolysis even when no acid is used [34] [81] [134]. However, as each hydrolysis-condensation reaction consumes a water molecule, enough water should be present, to add new hydroxyl groups on the surface of the forming silica-titania composites. Another way to slow down hydrolysis is by reacting the precursors first with molecules, like glycols, which are larger than the side-groups of the precursor. These molecules can replace the side-groups of the precursors [124] [135] if added in excess, so that new, less reactive titania precursors are formed. Depending on the exact method, another important variable is the speed at which a parameter is changed, for example, the change of $\mathrm{pH}$ during the neutralization method, the addition speed of a precursor during a sol-gel method and the speed at which the temperature increases during a hydrothermal treatment.

\subsection{Transformation to Crystalline Titania}

When the hydrolysis rate is very slow during the reaction, thermodynamics plays a more important role than kinetics. Since crystalline titania is more energetically favorable than amorphous titania, crystallization of the titania can then directly happen, especially at a low $\mathrm{pH}$, where the solubility difference between amorphous titania and crystalline titania is larger [122] [134] [136]-[143]. However, the direct formation of crystalline titania is hard to control. If the hydrolysis is too slow, it can result in large rutile crystals with a low specific surface area, which is undesirable for the photocatalysis. In any other case, it is likely that most of the titania is amorphous titania after the reaction. Because amorphous titania has a much lower photocatalytic activity [96] [99], it can be beneficial to either use calcination or hydrothermal treatment to transform it into anatase.

During the calcination of pure titania, the transformation of amorphous titania to anatase happens at a temperature of about $400^{\circ} \mathrm{C}$ and at temperatures above $600^{\circ} \mathrm{C}$ the transformation to rutile occurs [143]. At these high temperatures, chemically bonded hydroxyl groups condensate with each other so that more bonds are formed between the titanium and oxygen atoms. Through rearrangements, the crystal structures are then slowly formed. Once a crystal is large enough to be stable, it will further increase in size by taking up more titania atoms, either through more rearrangements, or by merging with other crystals.

Besides the calcination in dry air, it is also possible to use hydrothermal treatment for the formation of crystalline titania [25]-[31] [71] [72] [145]-[149]. Since the formation of crystalline titania takes place in an aqueous environment during a hydrothermal treatment hydroxyl groups are incorporated into the formed structure which can be helpful for the photocatalytic activity. Hydrothermal treatment works at lower temperatures than calcination because the water increases the mobility of the atoms, reduces surface tension of the titania and catalyzes nucleation of crystals [145]-[149]. Wang and Ying [147] showed that using a hydrothermal treatment on amorphous titania, smaller and more stable titania nanoparticles were produced than with calcination.

The exact temperature at which the transformation to either anatase or rutile happens during both calcination and hydrothermal treatment depends on the size of the particles (according to Banfield et al. [144] below a size 
of $14 \mathrm{~nm}$, anatase is more thermodynamically stable than rutile), the $\mathrm{pH}$ and other chemicals (e.g. adsorbed polymers, salts) that can influence the mobility of the atoms [117] [134] [136] [140] [142]. The formation of anatase or rutile from amorphous titania does not start at a single point where all amorphous material crystallizes into anatase or into rutile. By using higher temperatures, more amorphous titania will transform into anatase. However, higher temperatures will also transform anatase into rutile and increase the growth rate of the crystals, which leads to a smaller specific surface area [72] [134] [136]-[143].

When titania is chemically bonded to a substrate like silica, the substrate stabilizes the different structures of titania, and suppresses the transformation of amorphous titania to anatase and the transformation of anatase to rutile by decreasing the mobility of the titania atoms like an anchor [32] [33] [54] [72] [76] [80] [129]. Thus, higher temperatures are required to form anatase and rutile when titania is coated on silica. While more energy is needed for the formation of anatase from amorphous titania on a support, the anatase that is then formed has a higher thermal stability. It has even been reported that the anatase-rutile transformation only happens in some composites with a high temperature of $1000^{\circ} \mathrm{C}$ [54] [129]. The increase in temperature required for the crystalline transformations depends on the thickness of the titania, since a thicker layer is less influenced by the support [54]. For the titania-silica composites, the crystal growth by calcination can cause shrinkage stress when the titania structure shrinks due to the density increase and removal of chemically and physically adsorbed water. As the silica works like an anchor against the shrinkage, stress is produced on the structure which can lead to the breakage of some Ti-O-Si bonds [150].

\section{The Influence of Silica on Photocatalytic Titania in Low Titania Content Composites}

Titania-silica composites have more different properties than pure titania than simply a higher stability and a higher specific surface area, especially when the titania content is very low. Many researchers have studied the low titania composites because of these different properties. Anpo et al. [5] were one of the first who studied them. Using the CVD method on a porous silica glass, they found some interesting results which include: 1) below three layers, no anatase could be measured with X-ray diffraction, while it could still be present; 2) the band-gap became larger ( $4.1 \mathrm{eV}$ ) for just a monolayer titania; 3 ) the titanium was 4-coordinated in a tetrahedral structure instead of the 6-coordinated octahedral structure in pure anatase or rutile; 4) the tetrahedral titania with a large band gap catalyzed different reactions like the decomposition of $\mathrm{N}_{2} \mathrm{O}$ as will be explained in Section 4.1; and 5) the photocatalytic efficiency per amount of catalyst was much higher for low titania content composites, which will be explained in Section 4.3 .

\subsection{The Larger Band Gap and Its Influence on the Photocatalytic Activity}

The band gap of titania increases when going from bulk anatase to the tetrahedral titania. The normal band gap for crystalline titania is around $3.0-3.2 \mathrm{eV}$, but the measureable band gap from a very low amount of titania on the surface of silica can be much larger [5] [21] [68] [69] [151] [152]. There are two effects responsible for this increase. The first is the quantum size effect, which increases the band gap with decreasing crystal size, when the size is below $2 \mathrm{~nm}$ [68]. The second effect is caused by the difference in energy levels of the energy bands from silica and the energy bands from titania, close to the titania-silica interface [1] [21] [68]. Band gaps up to $4.1 \mathrm{eV} \mathrm{[5]} \mathrm{[69]} \mathrm{could} \mathrm{be} \mathrm{measured} \mathrm{due} \mathrm{to} \mathrm{these} \mathrm{two} \mathrm{effects.} \mathrm{When} \mathrm{the} \mathrm{band} \mathrm{gap} \mathrm{becomes} \mathrm{larger,} \mathrm{electrons} \mathrm{re-}$ quire more energy to be excited to the conduction band. For the applications that use sun-light or normal indoor light as the light source, this larger band gap is a disadvantage, since even less of the light spectra can then be absorbed.

On the other hand, the energy that is absorbed is used more efficiently because of the larger band gap. A larger band gap lowers the chance for recombination and increases the redox potentials of the excited electrons and holes. This higher redox potential increases the efficiency of the formation of the radical hydroxyl and superoxides molecules and enables the titania to catalyze different reactions [5] [17]-[20]. For example, Yamashita et al. [18] measured that pure titania transformed NO mostly into oxidized species, while NO decomposed to $\mathrm{N}_{2}$ and $\mathrm{O}_{2}$ in the presence of composites prepared with an ion-exchange method, in which titanium ions replaced silicon ions. In the same system [19] and similar systems with other zeolites [20], the same observation was made with the reaction of $\mathrm{CO}_{2}$ and $\mathrm{H}_{2} \mathrm{O}$. With the ion-exchange composites, methanol was mostly produced while methane was produced by the titania samples. Another example of the difference in catalytic reactions taking place is 
from a study by Gao et al. [17] who observed that in the presence of tetrahedral titania, methanol reacted to methyl formate $\left(\mathrm{C}_{2} \mathrm{H}_{4} \mathrm{O}_{2}\right)$ and formaldehyde $\left(\mathrm{CH}_{2} \mathrm{O}\right)$ while in the presence of octahedral titania, methanol reacted to dimethyl ether $\left(\mathrm{C}_{2} \mathrm{H}_{6} \mathrm{O}\right)$. While photocatalytic titania has some potential in reducing the amount of greenhouse gasses in air [153], these reactions show that the composites have an even greater potential to be useful against climate change.

\subsection{Higher Density of Hydroxyl Groups}

Binary metal oxides often have better catalytic properties than single metal oxides because they have extra acid sites on their surface in the form of hydroxyl groups [1] [154]. The titania-silica composites are one of those binary systems, and an increase in acid sites has been measured in several different studies [1] [18] [37] [56] [74] [80] [83]. The increase in hydroxyl groups is important for the photocatalytic activity and hydrophilicity as these depend on the amount of hydroxyl groups on the surface. Tanabe et al. [154] made the hypothesis that this increase in hydroxyl groups is caused by the difference in coordination numbers. The coordination number for silicon atoms in silica is 4 and for titanium atoms in crystalline titania it is 6 . So when titanium atoms are introduced in, or on silica in low amounts and form the tetrahedral structure, an excess of negative -2 charge per titanium atom is created. This excess charge causes Brönsted acidity on the surface after absorbing enough protons to compensate the charge. Walter et al. [82] showed, using neutron diffraction, that the number of hydroxyl groups is indeed affected when titanium atoms are introduced into the silica structure by the difference in coordination number. They showed an increase in hydroxyl groups mainly caused by the increase in strain in the structure. Liu et al. [74] and Doolin et al. [80] both used the sol-gel method to make titania-rich and titania-poor composites and compared them to pure titania and silica. They measured indeed an increase in Brönsted acidity in the composites especially where there were Ti-O-Si bonds, which was in agreement with Tanabe. However, for the titania-poor composites, the increase in acidity was lower than for titania-rich composites, which is in disagreement with the model of Tanabe. So far, no model has been proposed yet, that explains the extra hydroxyl groups better than the model of Tanebe et al., but these studies about the extra hydroxyl groups do show that the mechanism is related with the Ti-O-Si bond [1].

\subsection{Higher Photocatalytic Efficiency of Low Titania Content Composites}

Other researchers [17] [35] [62] [67] [81] [83] found similar results as Anpo et al. [5] on different low titania content composites and these researchers often observed an increase in photocatalytic efficiency per amount of catalyst compared to pure titania. The high efficiencies of these low titania content composites, which do not even have enough titania for a full monolayer, are caused by: 1) the high specific surface area of the silica supports used; 2) the ability of the silica to adsorb many molecules for longer times than titania, especially with the extra hydroxyl groups; 3) the fact that the titania is used more efficiently since all the titania is at the surface; 4) the higher redox potentials of the electrons and holes; and 5) the fact that silica can scatter the light to the titania without being able to absorb its energy. In addition, during the photocatalytic measurements in these studies, UV-light was used. The measurements using UV-light might not represent the applications which use sun-light as the light source, since the decrease of possible light absorption caused by the increase in band gap is less with UV-light.

\section{Conclusions}

The titania-silica composites are interesting materials because they have the potential to make photocatalytic materials more cost-effective. For the same level of photocatalytic activity, fewer resources have to be invested with the titania-silica composites than with pure titania. The titania-silica composites can, with less and cheaper material, have the same photocatalytic efficiency as pure titania for a longer time since the composites can have a higher photocatalytic efficiency, lower production costs and increased durability. The applications of the photocatalytic material including the applications that degrade pollutants, become then more attractive for companies to produce on a larger scale which can eventually lead to an overall improvement of the quality of air and water.

To obtain this cost-effective photocatalytic material, the titania-silica composites need to be synthesized with a method that has low production costs but still produces composites which have a high photocatalytic efficiency. 
- For a high efficiency, the method needs to deposit an anatase layer with thickness of maximum $5 \mathrm{~nm}$ on a large specific surface area. Any layer larger than $5 \mathrm{~nm}$ will have titania, which does not contribute to the photocatalysis, since it is too far away from the surface.

- If some of the crystal structure is rutile instead of anatase, it can have some increase in photocatalytic efficiency because of the separation of holes and electrons at the interface of the two forms. However, the amount of rutile should not be too high, as the lifetime and conductivity of excited electrons and holes in rutile are less favorable than in anatase.

- When the crystal size is too small, the titania may have an increase in band gap. While it has been reported that such an increase in band gap can cause higher photocatalytic efficiencies, it is important to note that it will make the titania absorb less visible light.

- The titania should be chemically bonded to a silica substrate which has a large specific surface area, high mechanical and thermal stability as well as low production costs.

- The most promising methods for low cost photocatalytic composites are the ones that involve hydrolysis (precipitation and sol-gel methods), as these methods ensure that more than one layer of titania can form without the need of expensive materials. However, the hydrolysis of titania precursors can be hard to control. The most important parameters on which the hydrolysis rate is dependent are the $\mathrm{pH}$, temperature, concentration of water and precursor, the speed at which these parameters are changed during the reaction (e.g. by addition of water) and the type of precursor used. How much influence each parameter has on the hydrolysis rate depends on the method used. It is important that the reaction speed of the hydrolysis should be slow enough so that the condensation of titania monomers on the substrate's surface is more likely to happen than polymerization between monomers.

- For the transformation of amorphous titania to anatase, calcination or hydrothermal treatment can be applied. The temperature and time required to obtain anatase crystals from amorphous titania depend on the mobility of the titania molecules, which can be influenced by: the chemical bonds to the silica, any nucleated crystals already present, and other chemicals present (e.g. adsorbed polymers, salts). While having more crystalline anatase is beneficial for the photocatalytic activity, crystallization does not always produce materials with a higher photocatalytic efficiency, since during the growth of the crystals, the specific surface area is reduced and anatase can transform into rutile at high temperatures.

When all these points are fulfilled, the resulting titania-silica composites will have the required properties to be a cost-effective material which can compete with pure titania in photocatalytic applications. Even with the increased complexity, the composites are an excellent alternative to pure titania nanoparticles.

\section{References}

[1] Gao, X. and Wachs, I.E. (1999) Titania-Silica as Catalysts: Molecular Structural Characteristics and Physico-Chemical Properties. Catalysis Today, 51, 233-254. http://dx.doi.org/10.1016/S0920-5861(99)00048-6

[2] Hüsken, G., Hunger, M. and Brouwers, H.J.H. (2009) Experimental Study of Photocatalytic Concrete Products for Air Purification. Building and environment, 44, 2463-2474. http://dx.doi.org/10.1016/j.buildenv.2009.04.010

[3] Fujishima, A., Zhang, X. and Tryk, D.A. (2008) $\mathrm{TiO}_{2}$ Photocatalysis and Related Surface Phenomena. Surface Science Reports, 63, 515-582. http://dx.doi.org/10.1016/j.surfrep.2008.10.001

[4] Hashimoto, K., Irie, H. and Fujishima, A. (2005). $\mathrm{TiO}_{2}$ Photocatalysis: A Historical Overview and Future Prospects. Japanese Journal of Applied Physics, 44, 8269. http://dx.doi.org/10.1143/JJAP.44.8269

[5] Anpo, M., Aikawa, N., Kubokawa, Y., Che, M., Louis, C. and Giamello, E. (1985) Photoluminescence and Photocatalytic Activity of Highly Dispersed Titanium Oxide Anchored onto Porous Vycor Glass. The Journal of Physical Chemistry, 89, 5017-5021. http://dx.doi.org/10.1021/j100269a025

[6] Fujishima, A., and Zhang, X. (2006) Titanium Dioxide Photocatalysis: Present Situation and Future Approaches. Comptes Rendus Chimie, 9, 750-760. http://dx.doi.org/10.1016/j.crci.2005.02.055

[7] Turchi, C.S. and Ollis, D.F. (1990) Photocatalytic Degradation of Organic Water Contaminants: Mechanisms Involving Hydroxyl Radical Attack. Journal of catalysis, 122, 178-192. http://dx.doi.org/10.1016/0021-9517(90)90269-P

[8] Ballari, M.M. and Brouwers, H.J.H. (2013) Full Scale Demonstration of Air-Purifying Pavement. Journal of hazardous materials, 254, 406-414. http://dx.doi.org/10.1016/j.jhazmat.2013.02.012

[9] Hüsken, G., Hunger, M., and Brouwers, H.J. (2007) Comparative Study on Cementitious Products Containing Titanium Dioxide as Photo-Catalyst. Proceedings of the International RILEM Symposium on Photocatalysis, Environment and Construction Materials-TDP, Florence, 8-9 October 2007, 147-154. 
[10] Hunger, M., Hüsken, G. and Brouwers, H.J.H. (2010) Photocatalytic Degradation of Air Pollutants—From Modeling to Large Scale Application. Cement and Concrete Research, 40, 313-320. http://dx.doi.org/10.1016/j.cemconres.2009.09.013

[11] Linsebigler, A.L., Lu, G. and Yates Jr., J.T. (1995) Photocatalysis on $\mathrm{TiO}_{2}$ Surfaces: Principles, Mechanisms, and Selected Results. Chemical Reviews, 95, 735-758. http://dx.doi.org/10.1021/cr00035a013

[12] Anpo, M., Aikawa, N., Kodama, S. and Kubokawa, Y. (1984) Photocatalytic Hydrogenation of Alkynes and Alkenes with Water over Titanium Dioxide. Hydrogenation Accompanied by Bond Fission. The Journal of Physical Chemistry, 88, 2569-2572. http://dx.doi.org/10.1021/j150656a028

[13] Sirikawinkobkul, N., Kalambaheti, C., Jiemsirilers, S., Kashima, D.P. and Jinawath, S. (2009) Synthesis, Characterization and Photocatalytic Activity of Visible-Light Titania/Silica Photocatalyst. 18th International Conference on Composite Materials, Edinburgh, 27-31 July 2009.

[14] Montes, M., Getton, F.P., Vong, M.S.W. and Sermon, P.A. (1997) Titania on Silica. A Comparison of Sol-Gel Routes and Traditional Methods. Journal of Sol-Gel Science and Technology, 8, 131-137. http://dx.doi.org/10.1007/BF02436830

[15] Huang, C.H., Bai, H., Liu, S.L., Huang, Y.L. and Tseng, Y.H. (2011) Synthesis of Neutral $\mathrm{SiO}_{2} / \mathrm{TiO}_{2}$ Hydrosol and Its Photocatalytic Degradation of Nitric Oxide Gas. Micro \& Nano Letters, 6, 646-649. http://dx.doi.org/10.1049/mnl.2011.0331

[16] Ding, Z., Lu, G.Q. and Greenfield, P.F. (2000) A Kinetic Study on Photocatalytic Oxidation of Phenol in Water by Silica-Dispersed Titania Nanoparticles. Journal of Colloid and Interface Science, 232, 1-9. http://dx.doi.org/10.1006/jcis.2000.7154

[17] Gao, X., Bare, S.R., Fierro, J.L.G., Banares, M.A. and Wachs, I.E. (1998) Preparation and In-Situ Spectroscopic Characterization of Molecularly Dispersed Titanium Oxide on Silica. The Journal of Physical Chemistry B, 102, 56535666. http://dx.doi.org/10.1021/jp981423e

[18] Yamashita, H., Ichihashi, Y., Anpo, M., Hashimoto, M., Louis, C. and Che, M. (1996) Photocatalytic Decomposition of NO at $275 \mathrm{~K}$ on Titanium Oxides Included within Y-Zeolite Cavities: The Structure and Role of the Active Sites. The Journal of Physical Chemistry, 100, 16041-16044. http://dx.doi.org/10.1021/jp9615969

[19] Anpo, M., Yamashita, H., Ichihashi, Y., Fujii, Y. and Honda, M. (1997) Photocatalytic Reduction of $\mathrm{CO}_{2}$ with $\mathrm{H}_{2} \mathrm{O}$ on Titanium Oxides Anchored within Micropores of Zeolites: Effects of the Structure of the Active Sites and the Addition of Pt. The Journal of Physical Chemistry B, 101, 2632-2636. http://dx.doi.org/10.1021/jp962696h

[20] Anpo, M., Yamashita, H., Ikeue, K., Fujii, Y., Zhang, S.G., Ichihashi, Y. and Tatsumi, T. (1998) Photocatalytic Reduction of $\mathrm{CO}_{2}$ with $\mathrm{H}_{2} \mathrm{O}$ on Ti-MCM-41 and Ti-MCM-48 Mesoporous Zeolite Catalysts. Catalysis Today, 44, $327-332$. http://dx.doi.org/10.1016/S0920-5861(98)00206-5

[21] Fernández, A., Caballero, A. and González-Elipe, A.R. (1992) Size and Support Effects in the Photoelectron Spectra of Small $\mathrm{TiO}_{2}$ Particles. Surface and Interface Analysis, 18, 392-396. http://dx.doi.org/10.1002/sia.740180604

[22] Anpo, M., Yamashita, H., Ichihashi, Y. and Ehara, S. (1995) Photocatalytic Reduction of $\mathrm{CO}_{2}$ with $\mathrm{H}_{2} \mathrm{O}$ on Various Titanium Oxide Catalysts. Journal of Electroanalytical Chemistry, 396, 21-26. http://dx.doi.org/10.1016/0022-0728(95)04141-A

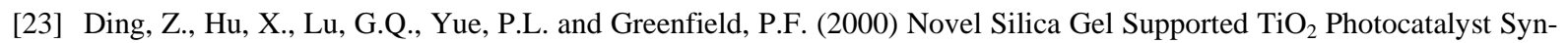
thesized by CVD Method. Langmuir, 16, 6216-6222. http://dx.doi.org/10.1021/la000119l

[24] Yamashita, H., Ichihashi, Y., Harada, M., Stewart, G., Fox, M.A. and Anpo, M. (1996) Photocatalytic Degradation of 1-Octanol on Anchored Titanium Oxide and on $\mathrm{TiO}_{2}$ Powder Catalysts. Journal of Catalysis, 158, 97-101. http://dx.doi.org/10.1006/jcat.1996.0010

[25] Sayilkan, F., Asilturk, M., Sener, S., Erdemoglu, S., Erdemoglu, M. and Sayilkan, H. (2007) Hydrothermal Synthesis, Characterization and Photocatalytic Activity of Nanosized $\mathrm{TiO}_{2}$ Based Catalysts for Rhodamine B Degradation. Turkish Journal of Chemistry, 31, 211-221.

[26] Chuan, X.Y., Hirano, M. and Inagaki, M. (2004) Preparation and Photocatalytic Performance of Anatase-Mounted Natural Porous Silica, Pumice, by Hydrolysis under Hydrothermal Conditions. Applied Catalysis B: Environmental, 51, 255-260. http://dx.doi.org/10.1016/j.apcatb.2004.03.004

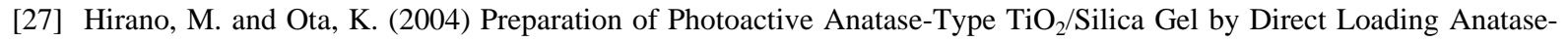
Type $\mathrm{TiO}_{2}$ Nanoparticles in Acidic Aqueous Solutions by Thermal Hydrolysis. Journal of Materials Science, 39, 18411844. http://dx.doi.org/10.1023/B:JMSC.0000016199.85213.0b

[28] Hirano, M. and Ota, K. (2004) Direct Formation and Photocatalytic Performance of Anatase $\left.\left(\mathrm{TiO}_{2}\right) / \mathrm{Silica}_{(\mathrm{SiO}}\right)$ Composite Nanoparticles. Journal of the American Ceramic Society, 87, 1567-1570. http://dx.doi.org/10.1111/j.1551-2916.2004.01567.X

[29] Kim, E.Y., Whang, C.M., Lee, W.I. and Kim, Y.H. (2006) Photocatalytic Property of $\mathrm{SiO}_{2} / \mathrm{TiO}_{2}$ Nanoparticles Pre- 
pared by Sol-Hydrothermal Process. Journal of Electroceramics, 17, 899-902.

http://dx.doi.org/10.1007/s10832-006-9071-5

[30] Fu, X., Clark, L.A., Yang, Q. and Anderson, M.A. (1996) Enhanced Photocatalytic Performance of Titania-Based Binary Metal Oxides: $\mathrm{TiO}_{2} / \mathrm{SiO}_{2}$ and $\mathrm{TiO}_{2} / \mathrm{ZrO}_{2}$. Environmental Science \& Technology, 30, 647-653. http://dx.doi.org/10.1021/es950391v

[31] Anderson, C. and Bard, A.J. (1995) An Improved Photocatalyst of $\mathrm{TiO}_{2} / \mathrm{SiO}_{2}$ Prepared by a Sol-Gel Synthesis. The Journal of Physical Chemistry, 99, 9882-9885. http://dx.doi.org/10.1021/j100024a033

[32] Cheng, P., Zheng, M.P., Huang, Q., Jin, Y.P. and Gu, M.Y. (2003) Enhanced Photoactivity of Silica-Titania Binary Oxides Prepared by Sol-Gel Method. Journal of Materials Science Letters, 22, 1165-1168. http://dx.doi.org/10.1023/A:1025187330150

[33] Smitha, V.S., Manjumol, K.A., Baiju, K.V., Ghosh, S., Perumal, P. and Warrier, K.G.K. (2010) Sol-Gel Route to Synthesize Titania-Silica Nano Precursors for Photoactive Particulates and Coatings. Journal of Sol-Gel Science and Technology, 54, 203-211. http://dx.doi.org/10.1007/s10971-010-2178-9

[34] Guo, X.C. and Dong, P. (1999) Multistep Coating of Thick Titania Layers on Monodisperse Silica Nanospheres. Langmuir, 15, 5535-5540. http://dx.doi.org/10.1021/la990220u

[35] Kamaruddin, S. and Stephan, D. (2014) Sol-Gel Mediated Coating and Characterization of Photocatalytic Sand and Fumed Silica for Environmental Remediation. Water, Air, \& Soil Pollution, 225, 1948. http://dx.doi.org/10.1007/s11270-014-1948-3

[36] Shan, A.Y., Ghazi, T.I.M. and Rashid, S.A. (2010) Immobilisation of Titanium Dioxide onto Supporting Materials in Heterogeneous Photocatalysis: A Review. Applied Catalysis A: General, 389, 1-8. http://dx.doi.org/10.1016/j.apcata.2010.08.053

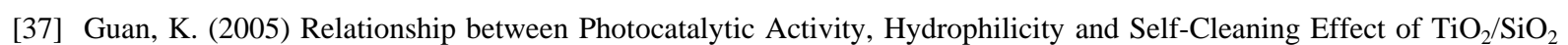
Films. Surface and Coatings Technology, 191, 155-160. http://dx.doi.org/10.1016/j.surfcoat.2004.02.022

[38] Jung, K.Y. and Park, S.B. (2000) Enhanced Photoactivity of Silica-Embedded Titania Particles Prepared by Sol-Gel Process for the Decomposition of Trichloroethylene. Applied Catalysis B: Environmental, 25, 249-256. http://dx.doi.org/10.1016/S0926-3373(99)00134-4

[39] Ismail, A.A., Ibrahim, I.A., Ahmed, M.S., Mohamed, R.M. and El-Shall, H. (2004) Sol-Gel Synthesis of Titania-Silica Photocatalyst for Cyanide Photodegradation. Journal of Photochemistry and Photobiology A: Chemistry, 163, 445-451. http://dx.doi.org/10.1016/j.jphotochem.2004.01.017

[40] Xie, C., Xu, Z., Yang, Q., Xue, B., Du, Y. and Zhang, J. (2004) Enhanced Photocatalytic Activity of Titania-Silica Mixed Oxide Prepared via Basic Hydrolyzation. Materials Science and Engineering: B, 112, 34-41. http://dx.doi.org/10.1016/j.mseb.2004.05.011

[41] Zhang, X., Zhang, F. and Chan, K.Y. (2005) Synthesis of Titania-Silica Mixed Oxide Mesoporous Materials, Characterization and Photocatalytic Properties. Applied Catalysis A: General, 284, 193-198. http://dx.doi.org/10.1016/j.apcata.2005.01.037

[42] Yang, J., Zhang, J., Zhu, L., Chen, S., Zhang, Y., Tang, Y. and Li, Y. (2006) Synthesis of Nano Titania Particles Embedded in Mesoporous SBA-15: Characterization and Photocatalytic Activity. Journal of Hazardous Materials, 137, 952-958. http://dx.doi.org/10.1016/j.jhazmat.2006.03.017

[43] Maggos, T., Plassais, A., Bartzis, J.G., Vasilakos, C., Moussiopoulos, N. and Bonafous, L. (2008) Photocatalytic Degradation of $\mathrm{NO}_{\mathrm{x}}$ in a Pilot Street Canyon Configuration Using $\mathrm{TiO}_{2}$-Mortar Panels. Environmental Monitoring and Assessment, 136, 35-44. http://dx.doi.org/10.1007/s10661-007-9722-2

[44] Strini, A., Cassese, S. and Schiavi, L. (2005) Measurement of Benzene, Toluene, Ethylbenzene and o-Xylene Gas Phase Photodegradation by Titanium Dioxide Dispersed in Cementitious Materials Using a Mixed Flow Reactor. Applied Catalysis B: Environmental, 61, 90-97. http://dx.doi.org/10.1016/j.apcatb.2005.04.009

[45] Ângelo, J., Andrade, L. and Mendes, A. (2014) Highly Active Photocatalytic Paint for $\mathrm{NO}_{\mathrm{x}}$ Abatement under Real-Outdoor Conditions. Applied Catalysis A: General, 484, 17-25. http://dx.doi.org/10.1016/j.apcata.2014.07.005

[46] Chen, J. and Poon, C.S. (2009) Photocatalytic Construction and Building Materials: From Fundamentals to Applications. Building and Environment, 44, 1899-1906. http://dx.doi.org/10.1016/j.buildenv.2009.01.002

[47] Paz, Y. (2010) Application of $\mathrm{TiO}_{2}$ Photocatalysis for Air Treatment: Patents' Overview. Applied Catalysis B: Environmental, 99, 448-460. http://dx.doi.org/10.1016/j.apcatb.2010.05.011

[48] Yu, Q.L. and Brouwers, H.J.H. (2009) Indoor Air Purification Using Heterogeneous Photocatalytic Oxidation. Part I: Experimental Study. Applied Catalysis B: Environmental, 92, 454-461. http://dx.doi.org/10.1016/j.apcatb.2009.09.004

[49] Yu, Q.L. and Brouwers, H.J.H. (2013) Design of a Novel Photocatalytic Gypsum Plaster: With the Indoor Air Purification Property. Advanced Materials Research, 651,751-756. http://dx.doi.org/10.4028/www.scientific.net/AMR.651.751 
[50] Poon, C.S. and Cheung, E. (2007) NO Removal Efficiency of Photocatalytic Paving Blocks Prepared with Recycled Materials. Construction and Building Materials, 21, 1746-1753. http://dx.doi.org/10.1016/j.conbuildmat.2006.05.018

[51] de Melo, J.V.S., Trichês, G., Gleize, P.J.P. and Villena, J. (2012) Development and Evaluation of the Efficiency of Photocatalytic Pavement Blocks in the Laboratory and after One Year in the Field. Construction and Building Materials, 37, 310-319. http://dx.doi.org/10.1016/j.conbuildmat.2012.07.073

[52] Castillo, R., Koch, B., Ruiz, P. and Delmon, B. (1994) Influence of Preparation Methods on the Texture and Structure of Titania Supported on Silica. Journal of Materials Chemistry, 4, 903-906. http://dx.doi.org/10.1039/jm9940400903

[53] Morrison, C. and Kiwi, J. (1989) Preparation and Characterization of $\mathrm{TiO}_{2}-\mathrm{SiO}_{2}$ Aerosil Colloidal Mixed Dispersions. Journal of the Chemical Society, Faraday Transactions 1: Physical Chemistry in Condensed Phases, 85, 1043-1048. http://dx.doi.org/10.1039/f19898501043

[54] Hsu, W.P., Yu, R. and Matijević, E. (1993) Paper Whiteners: I. Titania Coated Silica. Journal of Colloid and Interface Science, 156, 56-65. http://dx.doi.org/10.1006/jcis.1993.1080

[55] Galan-Fereres, M., Mariscal, R., Alemany, L.J., Fierro, J.L.G. and Anderson, J.A. (1994) Ternary V-Ti-Si Catalysts and Their Behaviour in the CO + NO Reaction. Journal of the Chemical Society, Faraday Transactions, 90, 3711-3718. http://dx.doi.org/10.1039/ft9949003711

[56] Galan-Fereres, M., Alemany, L.J., Mariscal, R., Banares, M.A., Anderson, J.A. and Fierro, J.L. (1995) Surface Acidity and Properties of Titania-Silica Catalysts. Chemistry of Materials, 7, 1342-1348. http://dx.doi.org/10.1021/cm00055a011

[57] Choi, H.H., Park, J. and Singh, R.K. (2005) Nanosized Titania Encapsulated Silica Particles Using an Aqueous $\mathrm{TiCl}_{4}$ Solution. Applied Surface Science, 240, 7-12. http://dx.doi.org/10.1016/j.apsusc.2004.06.147

[58] Sun, Z., Bai, C., Zheng, S., Yang, X. and Frost, R.L. (2013) A Comparative Study of Different Porous Amorphous Silica Minerals Supported $\mathrm{TiO}_{2}$ Catalysts. Applied Catalysis A: General, 458, 103-110. http://dx.doi.org/10.1016/j.apcata.2013.03.035

[59] Srinivasan, S., Datye, A.K., Hampden-Smith, M., Wachs, I.E., Deo, G., Jehng, J.M., Turek, A.M. and Peden, C.H.F. (1991) The Formation of Titanium Oxide Monolayer Coatings on Silica Surfaces. Journal of Catalysis, 131, 260-275. http://dx.doi.org/10.1016/0021-9517(91)90343-3

[60] Srinivasan, S., Datye, A.K., Smith, M.H. and Peden, C.H.F. (1994) Interaction of Titanium Isopropoxide with Surface Hydroxyls on Silica. Journal of Catalysis, 145, 565-573. http://dx.doi.org/10.1006/jcat.1994.1068

[61] Mariscal, R., Palacios, J.M., Galan-Fereres, M. and Fierro, J.L.G. (1994) Incorporation of Titania into Preshaped Silica Monolith Structures. Applied Catalysis A: General, 116, 205-219. http://dx.doi.org/10.1016/0926-860X(94)80290-4

[62] Salama, T.M., Tanaka, T., Yamaguchi, T. and Tanabe, K. (1990) EXAFS/XANES Study of Titanium Oxide Supported on $\mathrm{SiO}_{2}$ : A Structural Consideration on the Amorphous State. Surface Science, 227, L100-L104. http://dx.doi.org/10.1016/0039-6028(90)90379-m

[63] Ellestad, O.H. and Blindheim, U. (1985) Reactions of Titanium Tetrachloride with Silica Gel Surfaces. Journal of Molecular Catalysis, 33, 275-287. http://dx.doi.org/10.1016/0304-5102(85)85001-X

[64] Aronson, B.J., Blanford, C.F. and Stein, A. (1997) Solution-Phase Grafting of Titanium Dioxide onto the Pore Surface of Mesoporous Silicates: Synthesis and Structural Characterization. Chemistry of Materials, 9, 2842-2851. http://dx.doi.org/10.1021/cm970180k

[65] Huang, Y.Y., Zhao, B.Y. and Xie, Y.C. (1998) A Novel Way to Prepare Silica Supported Sulfated Titania. Applied Catalysis A: General, 171, 65-73. http://dx.doi.org/10.1016/S0926-860X(98)00071-4

[66] Morrow, B.A. and McFarlan, A.J. (1990) Chemical Reactions at Silica Surfaces. Journal of Non-Crystalline Solids, 120, 61-71. http://dx.doi.org/10.1016/0022-3093(90)90191-N

[67] Haukka, S., Lakomaa, E.L. and Root, A. (1993) An IR and NMR Study of the Chemisorption of Titanium Tetrachloride on Silica. The Journal of Physical Chemistry, 97, 5085-5094. http://dx.doi.org/10.1021/j100121a040

[68] Nakayama, T., Onisawa, K., Fuyama, M. and Hanazono, M. (1992) $\mathrm{TiO}_{2} / \mathrm{SiO}_{2}$ Multilayer Insulating Films for ELDs. Journal of the Electrochemical Society, 139, 1204-1206. http://dx.doi.org/10.1149/1.2069367

[69] Lassaletta, G., Fernandez, A., Espinos, J.P. and Gonzalez-Elipe, A.R. (1995) Spectroscopic Characterization of Quantum-Sized $\mathrm{TiO}_{2}$ Supported on Silica: Influence of Size and $\mathrm{TiO}_{2}-\mathrm{SiO}_{2}$ Interface Composition. The Journal of Physical Chemistry, 99, 1484-1490. http://dx.doi.org/10.1021/j100005a019

[70] Nakayama, T. (1994) Structure of $\mathrm{TiO}_{2} / \mathrm{SiO}_{2}$ Multilayer Films. Journal of the Electrochemical Society, 141, $237-241$. http://dx.doi.org/10.1149/1.2054690

[71] Hayashi, T., Yamada, T. and Saito, H. (1983) Preparation of Titania-Silica Glasses by the Gel Method. Journal of Materials Science, 18, 3137-3142. http://dx.doi.org/10.1007/BF00700798 
[72] Li, Z., Hou, B., Xu, Y., Wu, D., Sun, Y., Hu, W. and Deng, F. (2005) Comparative Study of Sol-Gel-Hydrothermal and Sol-Gel Synthesis of Titania-Silica Composite Nanoparticles. Journal of Solid State Chemistry, 178, 1395-1405. http://dx.doi.org/10.1016/j.jssc.2004.12.034

[73] Fu, X. and Qutubuddin, S. (2001) Synthesis of Titania-Coated Silica Nanoparticles Using a Nonionic Water-in-Oil Microemulsion. Colloids and Surfaces A: Physicochemical and Engineering Aspects, 179, 65-70. http://dx.doi.org/10.1016/S0927-7757(00)00723-8

[74] Liu, Z.F., Tabora, J. and Davis, R.J. (1994) Relationships between Microstructure and Surface Acidity of Ti-Si Mixed Oxide Catalysts. Journal of Catalysis, 149, 117-126. http://dx.doi.org/10.1006/jcat.1994.1277

[75] Mine, E., Hirose, M., Kubo, M., Kobayashi, Y., Nagao, D. and Konno, M. (2006) Synthesis of Submicron-Sized Titania-Coated Silica Particles with a Sol-Gel Method and Their Application to Colloidal Photonic Crystals. Journal of Sol-Gel Science and Technology, 38, 91-95. http://dx.doi.org/10.1007/s10971-006-5855-y

[76] Lee, D.W., Ihm, S.K. and Lee, K.H. (2005) Mesostructure Control Using a Titania-Coated Silica Nanosphere Framework with Extremely High Thermal Stability. Chemistry of Materials, 17, 4461-4467. http://dx.doi.org/10.1021/cm050485w

[77] Lee, J.W., Kong, S., Kim, W.S. and Kim, J. (2007) Preparation and Characterization of $\mathrm{SiO}_{2} / \mathrm{TiO}_{2}$ Core-Shell Particles with Controlled Shell Thickness. Materials Chemistry and Physics, 106, 39-44. http://dx.doi.org/10.1016/j.matchemphys.2007.05.019

[78] Do Kim, K., Bae, H.J. and Kim, H.T. (2003) Synthesis and Characterization of Titania-Coated Silica Fine Particles by Semi-Batch Process. Colloids and Surfaces A: Physicochemical and Engineering Aspects, 224, 119-126. http://dx.doi.org/10.1016/S0927-7757(03)00252-8

[79] Rupp, W., Hüsing, N. and Schubert, U. (2002) Preparation of Silica-Titania Xerogels and Aerogels by Sol-Gel Processing of New Single-Source Precursors. Journal of Materials Chemistry, 12, 2594-2596. http://dx.doi.org/10.1039/b204956b

[80] Doolin, P.K., Alerasool, S., Zalewski, D.J. and Hoffman, J.F. (1994) Acidity Studies of Titania-Silica Mixed Oxides. Catalysis Letters, 25, 209-223. http://dx.doi.org/10.1007/BF00816302

[81] Hanprasopwattana, A., Srinivasan, S., Sault, A.G. and Datye, A.K. (1996) Titania Coatings on Monodisperse Silica Spheres (Characterization Using 2-Propanol Dehydration and TEM). Langmuir, 12, 3173-3179. http://dx.doi.org/10.1021/la950808a

[82] Walters, J.K., Rigden, J.S., Dirken, P.J., Smith, M.E., Howells, W.S. and Newport, R.J. (1997) An Atomic-Scale Study of the Role of Titanium in $\mathrm{TiO}_{2}: \mathrm{SiO}_{2}$ Sol-Gel Materials. Chemical Physics Letters, 264, 539-544. http://dx.doi.org/10.1016/S0009-2614(96)01359-0

[83] Klein, S., Weckhuysen, B.M., Martens, J.A., Maier, W.F. and Jacobs, P.A. (1996) Homogeneity of Titania-Silica Mixed Oxides: On UV-DRS Studies as a Function of Titania Content. Journal of Catalysis, 163, 489-491. http://dx.doi.org/10.1006/jcat.1996.0350

[84] Liu, G., Liu, Y., Yang, G., Li, S., Zu, Y., Zhang, W. and Jia, M. (2009) Preparation of Titania-Silica Mixed Oxides by a Sol-Gel Route in the Presence of Citric Acid. The Journal of Physical Chemistry C, 113, 9345-9351. http://dx.doi.org/10.1021/jp900577c

[85] Fujishima, A., Rao, T.N. and Tryk, D.A. (2000) Titanium Dioxide Photocatalysis. Journal of Photochemistry and Photobiology C: Photochemistry Reviews, 1, 1-21. http://dx.doi.org/10.1016/S1389-5567(00)00002-2

[86] Carp, O., Huisman, C.L. and Reller, A. (2004) Photoinduced Reactivity of Titanium Dioxide. Progress in Solid State Chemistry, 32, 33-177. http://dx.doi.org/10.1016/j.progsolidstchem.2004.08.001

[87] Kitano, M., Matsuoka, M., Ueshima, M. and Anpo, M. (2007) Recent Developments in Titanium Oxide-Based Photocatalysts. Applied Catalysis A: General, 325, 1-14. http://dx.doi.org/10.1016/j.apcata.2007.03.013

[88] Gaya, U.I. and Abdullah, A.H. (2008) Heterogeneous Photocatalytic Degradation of Organic Contaminants over Titanium Dioxide: A Review of Fundamentals, Progress and Problems. Journal of Photochemistry and Photobiology C: Photochemistry Reviews, 9, 1-12. http://dx.doi.org/10.1016/j.jphotochemrev.2007.12.003

[89] Macwan, D.P., Dave, P.N. and Chaturvedi, S. (2011) A Review on Nano- $\mathrm{TiO}_{2}$ Sol-Gel Type Syntheses and Its Applications. Journal of Materials Science, 46, 3669-3686. http://dx.doi.org/10.1007/s10853-011-5378-y

[90] Simonsen, M.E., Li, Z. and Søgaard, E.G. (2009) Influence of the OH Groups on the Photocatalytic Activity and Photoinduced Hydrophilicity of Microwave Assisted Sol-Gel TiO ${ }_{2}$ Film. Applied Surface Science, 255, 8054-8062. http://dx.doi.org/10.1016/j.apsusc.2009.05.013

[91] Yu, J., Jimmy, C.Y., Ho, W. and Jiang, Z. (2002) Effects of Calcination Temperature on the Photocatalytic Activity and Photo-Induced Super-Hydrophilicity of Mesoporous $\mathrm{TiO}_{2}$ Thin Films. New Journal of Chemistry, 26, 607-613. http://dx.doi.org/10.1039/b200964a 
[92] Wang, R., Hashimoto, K., Fujishima, A., Chikuni, M., Kojima, E., Kitamura, A. and Watanabe, T. (1997) Light-Induced Amphiphilic Surfaces. Nature, 388, 431-432. http://dx.doi.org/10.1038/41233

[93] Mezhenny, S., Maksymovych, P., Thompson, T.L., Diwald, O., Stahl, D., Walck, S.D. and Yates, J.T. (2003) STM Studies of Defect Production on the $\mathrm{TiO}_{2}(110)-(1 \times 1)$ and $\mathrm{TiO}_{2}(110)-(1 \times 2)$ Surfaces Induced by UV Irradiation. Chemical Physics Letters, 369, 152-158. http://dx.doi.org/10.1016/S0009-2614(02)01997-8

[94] White, J.M., Szanyi, J. and Henderson, M.A. (2003) The Photon-Driven Hydrophilicity of Titania: A Model Study Using $\mathrm{TiO}_{2}(110)$ and Adsorbed Trimethyl Acetate. The Journal of Physical Chemistry B, 107, 9029-9033. http://dx.doi.org/10.1021/jp0345046

[95] Miyauchi, M., Nakajima, A., Fujishima, A., Hashimoto, K. and Watanabe, T. (2000) Photoinduced Surface Reactions on $\mathrm{TiO}_{2}$ and $\mathrm{SrTiO}_{3}$ Films: Photocatalytic Oxidation and Photoinduced Hydrophilicity. Chemistry of Materials, 12, 3-5. http://dx.doi.org/10.1021/cm990556p

[96] Luttrell, T., Halpegamage, S., Tao, J., Kramer, A., Sutter, E. and Batzill, M. (2014) Why Is Anatase a Better Photocatalyst than Rutile?-Model Studies on Epitaxial $\mathrm{TiO}_{2}$ Films. Scientific Reports, 4, Article No.: 4043. http://dx.doi.org/10.1038/srep04043

[97] Mattioli, G., Filippone, F., Alippi, P. and Bonapasta, A.A. (2008) Ab Initio Study of the Electronic States Induced by Oxygen Vacancies in Rutile and Anatase $\mathrm{TiO}_{2}$. Physical Review B, 78, Article ID: 241201. http://dx.doi.org/10.1103/PhysRevB.78.241201

[98] Xu, M., Gao, Y., Moreno, E.M., Kunst, M., Muhler, M., Wang, Y., Idriss, H. and Wöll, C. (2011) Photocatalytic Activity of Bulk $\mathrm{TiO}_{2}$ Anatase and Rutile Single Crystals Using Infrared Absorption Spectroscopy. Physical Review Letters, 106, Article ID: 138302. http://dx.doi.org/10.1103/PhysRevLett.106.138302

[99] Ohtani, B., Ogawa, Y. and Nishimoto, S.I. (1997) Photocatalytic Activity of Amorphous-Anatase Mixture of Titanium (IV) Oxide Particles Suspended in Aqueous Solutions. The Journal of Physical Chemistry B, 101, 3746-3752. http://dx.doi.org/10.1021/jp962702+

[100] Bickley, R.I., Gonzalez-Carreno, T., Lees, J.S., Palmisano, L. and Tilley, R.J. (1991) A Structural Investigation of Titanium Dioxide Photocatalysts. Journal of Solid State Chemistry, 92, 178-190. http://dx.doi.org/10.1016/0022-4596(91)90255-G

[101] Scanlon, D.O., Dunnill, C.W., Buckeridge, J., Shevlin, S.A., Logsdail, A.J., Woodley, S.M. and Sokol, A.A. (2013) Band Alignment of Rutile and Anatase $\mathrm{TiO}_{2}$. Nature Materials, 12, 798-801. http://dx.doi.org/10.1038/nmat3697

[102] Mogyorósi, K., Farkas, A., Dékány, I., Ilisz, I. and Dombi, A. (2002) $\mathrm{TiO}_{2}$-Based Photocatalytic Degradation of 2-Chlorophenol Adsorbed on Hydrophobic Clay. Environmental Science \& Technology, 36, 3618-3624. http://dx.doi.org/10.1021/es015843k

[103] Mogyorosi, K., Dekany, I. and Fendler, J.H. (2003) Preparation and Characterization of Clay Mineral Intercalated Titanium Dioxide Nanoparticles. Langmuir, 19, 2938-2946. http://dx.doi.org/10.1021/la025969a

[104] Kun, R., Mogyorósi, K. and Dékány, I. (2006) Synthesis and Structural and Photocatalytic Properties of TiO $2 / \mathrm{Mont}^{-}$ morillonite Nanocomposites. Applied Clay Science, 32, 99-110. http://dx.doi.org/10.1016/j.clay.2005.09.007

[105] Kibanova, D., Trejo, M., Destaillats, H. and Cervini-Silva, J. (2009) Synthesis of Hectorite-TiO ${ }_{2}$ and $\mathrm{Kaolinite}^{-T i O}{ }_{2}$ Nanocomposites with Photocatalytic Activity for the Degradation of Model Air Pollutants. Applied Clay Science, 42, 563-568. http://dx.doi.org/10.1016/j.clay.2008.03.009

[106] Matthews, R.W. (1991) Photooxidative Degradation of Coloured Organics in Water Using Supported Catalysts. TiO ${ }_{2}$ on Sand. Water Research, 25, 1169-1176. http://dx.doi.org/10.1016/0043-1354(91)90054-T

[107] Matthews, R.W. and McEvoy, S.R. (1992) Photocatalytic Degradation of Phenol in the Presence of Near-UV Illuminated Titanium Dioxide. Journal of Photochemistry and Photobiology A: Chemistry, 64, 231-246. http://dx.doi.org/10.1016/1010-6030(92)85110-G

[108] European Commission (2007) Reference Document on Best Available Techniques for the Manufacture of Large Volume Inorganic Chemicals_-Solids and Other Industry

[109] Iler, R.K. (1979) The Chemistry of Silica: Solubility, Polymerization, Colloid and Surface Properties, and Biochemistry. Wiley, New York.

[110] Stöber, W., Fink, A. and Bohn, E. (1968) Controlled Growth of Monodisperse Silica Spheres in the Micron Size Range. Journal of Colloid and Interface Science, 26, 62-69. http://dx.doi.org/10.1016/0021-9797(68)90272-5

[111] Lazaro, A., Brouwers, H.J.H., Quercia, G. and Geus, J.W. (2012) The Properties of Amorphous Nano-Silica Synthesized by the Dissolution of Olivine. Chemical Engineering Journal, 211, 112-121. http://dx.doi.org/10.1016/j.cej.2012.09.042

[112] Lazaro, A., Van de Griend, M.C., Brouwers, H.J.H. and Geus, J.W. (2013) The Influence of Process Conditions and Ostwald Ripening on the Specific Surface Area of Olivine Nano-Silica. Microporous and Mesoporous Materials, 181, 
254-261. http://dx.doi.org/10.1016/j.micromeso.2013.08.006

[113] Lazaro, A., Quercia, G., Brouwers, H. and Geus, J. (2013) Synthesis of a Green Nano-Silica Material Using Beneficiated Waste Dunites and Its Application in Concrete. World Journal of Nano Science and Engineering, 3, 41-51. http://dx.doi.org/10.4236/wjnse.2013.33006

[114] Lazaro, A., Benac-Vegas, L., Brouwers, H.J.H., Geus, J.W. and Bastida, J. (2015) The Kinetics of the Olivine Dissolution under the Extreme Conditions of Nano-Silica Production. Applied Geochemistry, 52, 1-15. http://dx.doi.org/10.1016/j.apgeochem.2014.10.015

[115] Gu, W. and Tripp, C.P. (2005) Role of Water in the Atomic Layer Deposition of $\mathrm{TiO}_{2}$ on $\mathrm{SiO}_{2}$. Langmuir, 21, $211-216$. http://dx.doi.org/10.1021/la047811r

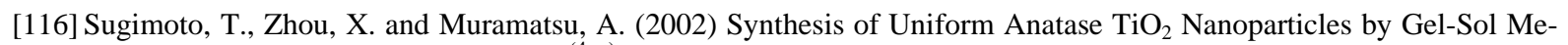
thod: 1. Solution Chemistry of $\mathrm{Ti}(\mathrm{OH})_{n}{ }^{(4-n)+}$ Complexes. Journal of Colloid and Interface Science, 252, 339-346. http://dx.doi.org/10.1006/jcis.2002.8454

[117] Lee, G.H. and Zuo, J.M. (2004) Growth and Phase Transformation of Nanometer-Sized Titanium Oxide Powders Produced by the Precipitation Method. Journal of the American Ceramic Society, 87, 473-479. http://dx.doi.org/10.1111/j.1551-2916.2004.00473.x

[118] Wang, T.H., Navarrete-López, A.M., Li, S., Dixon, D.A. and Gole, J.L. (2010) Hydrolysis of TiCl 4 : Initial Steps in the Production of $\mathrm{TiO}_{2}$. The Journal of Physical Chemistry A, 114, 7561-7570. http://dx.doi.org/10.1021/jp102020h

[119] Yoldas, B.E. (1986) Hydrolysis of Titanium Alkoxide and Effects of Hydrolytic Polycondensation Parameters. Journal of Materials Science, 21, 1087-1092. http://dx.doi.org/10.1007/BF01117399

[120] Zhang, X.T., Sato, O., Taguchi, M., Einaga, Y., Murakami, T. and Fujishima, A. (2005) Self-Cleaning Particle Coating with Antireflection Properties. Chemistry of Materials, 17, 696-700. http://dx.doi.org/10.1021/cm0484201

[121] Ryu, D.H., Kim, S.C., Koo, S.M. and Kim, D.P. (2003) Deposition of Titania Nanoparticles on Spherical Silica. Journal of Sol-Gel Science and Technology, 26, 489-493. http://dx.doi.org/10.1023/A:1020791130557

[122] Bischoff, B.L. and Anderson, M.A. (1995) Peptization Process in the Sol-Gel Preparation of Porous Anatase (TiO 2 ). Chemistry of Materials, 7, 1772-1778. http://dx.doi.org/10.1021/cm00058a004

[123] Mahshid, S., Askari, M. and Ghamsari, M.S. (2007) Synthesis of $\mathrm{TiO}_{2}$ Nanoparticles by Hydrolysis and Peptization of Titanium Isopropoxide Solution. Journal of Materials Processing Technology, 189, 296-300. http://dx.doi.org/10.1016/j.jmatprotec.2007.01.040

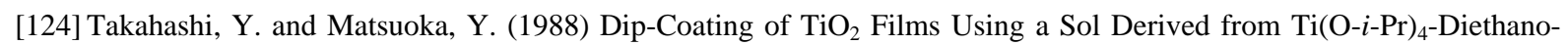
lamine- $\mathrm{H}_{2} \mathrm{O}-\mathrm{i}$-PrOH System. Journal of Materials Science, 23, 2259-2266. http://dx.doi.org/10.1007/BF01115798

[125] Kato, K., Tsuzuki, A., Taoda, H., Torii, Y., Kato, T. and Butsugan, Y. (1994) Crystal Structures of TiO ${ }_{2}$ Thin Coatings Prepared from the Alkoxide Solution via the Dip-Coating Technique Affecting the Photocatalytic Decomposition of Aqueous Acetic Acid. Journal of Materials Science, 29, 5911-5915. http://dx.doi.org/10.1007/BF00366875

[126] Imoberdorf, G.E., Irazoqui, H.A., Cassano, A.E. and Alfano, O.M. (2005) Photocatalytic Degradation of Tetrachloroethylene in Gas Phase on $\mathrm{TiO}_{2}$ Films: A Kinetic Study. Industrial \& Engineering Chemistry Research, 44, 6075-6085. http://dx.doi.org/10.1021/ie049185z

[127] Negishi, N., Takeuchi, K. and Ibusuki, T. (1998) Preparation of the $\mathrm{TiO}_{2}$ Thin Film Photocatalyst by the Dip-Coating Process. Journal of Sol-Gel Science and Technology, 13, 691-694. http://dx.doi.org/10.1023/A:1008640905357

[128] Negishi, N. and Takeuchi, K. (2001) Preparation of $\mathrm{TiO}_{2}$ Thin Film Photocatalysts by Dip Coating Using a Highly Viscous Solvent. Journal of Sol-Gel Science and Technology, 22, 23-31. http://dx.doi.org/10.1023/A:1011204001482

[129] Kim, D.J., Hahn, S.H., Oh, S.H. and Kim, E.J. (2002) Influence of Calcination Temperature on Structural and Optical Properties of $\mathrm{TiO}_{2}$ Thin Films Prepared by Sol-Gel Dip Coating. Materials Letters, 57, 355-360. http://dx.doi.org/10.1016/S0167-577X(02)00790-5

[130] Sonawane, R.S., Hegde, S.G. and Dongare, M.K. (2003) Preparation of Titanium (IV) Oxide Thin Film Photocatalyst by Sol-Gel Dip Coating. Materials Chemistry and Physics, 77, 744-750. http://dx.doi.org/10.1016/S0254-0584(02)00138-4

[131] Daoud, W.A. and Xin, J.H. (2004) Low Temperature Sol-Gel Processed Photocatalytic Titania Coating. Journal of Sol-Gel Science and Technology, 29, 25-29. http://dx.doi.org/10.1023/B:JSST.0000016134.19752.b4

[132] Crepaldi, E.L., Soler-Illia, G.J.D.A., Grosso, D., Cagnol, F., Ribot, F. and Sanchez, C. (2003) Controlled Formation of Highly Organized Mesoporous Titania Thin Films: From Mesostructured Hybrids to Mesoporous Nanoanatase $\mathrm{TiO}_{2}$. Journal of the American Chemical Society, 125, 9770-9786. http://dx.doi.org/10.1021/ja030070g

[133] Kajihara, K., Nakanishi, K., Tanaka, K., Hirao, K. and Soga, N. (1998) Preparation of Macroporous Titania Films by a Sol-Gel Dip-Coating Method from the System Containing Poly(ethylene glycol). Journal of the American Ceramic Society, 81, 2670-2676. http://dx.doi.org/10.1111/j.1151-2916.1998.tb02675.x 
[134] Park, H.K., Kim, D.K. and Kim, C.H. (1997) Effect of Solvent on Titania Particle Formation and Morphology in Thermal Hydrolysis of $\mathrm{TiCl}_{4}$. Journal of the American Ceramic Society, 80, 743-749. http://dx.doi.org/10.1111/j.1151-2916.1997.tb02891.x

[135] Jiang, X., Herricks, T. and Xia, Y. (2003) Monodispersed Spherical Colloids of Titania: Synthesis, Characterization, and Crystallization. Advanced Materials, 15, 1205-1209. http://dx.doi.org/10.1002/adma.200305105

[136] Sun, J. and Gao, L. (2002) pH Effect on Titania-Phase Transformation of Precipitates from Titanium Tetrachloride Solutions. Journal of the American Ceramic Society, 85, 2382-2384. http://dx.doi.org/10.1111/j.1151-2916.2002.tb00467.x

[137] Matthews, A. (1976) The Crystallization of Anatase and Rutile from Amorphous Titanium Dioxide under Hydrothermal Conditions. American Mineralogist, 61, 419-424.

[138] Nam, H.D., Lee, B.H., Kim, S.J., Jung, C.H., Lee, J.H. and Park, S. (1998) Preparation of Ultrafine $\mathrm{Crystalline} \mathrm{TiO}_{2}$ Powders from Aqueous $\mathrm{TiCl}_{4}$ Solution by Precipitation. Japanese Journal of Applied Physics, 37, 4603-4608. http://dx.doi.org/10.1143/JJAP.37.4603

[139] Pedraza, F. and Vazquez, A. (1999) Obtention of $\mathrm{TiO}_{2}$ Rutile at Room Temperature through Direct Oxidation of $\mathrm{TiCl}_{3}$. Journal of Physics and Chemistry of Solids, 60, 445-448. http://dx.doi.org/10.1016/S0022-3697(98)00315-1

[140] Terabe, K., Kato, K., Miyazaki, H., Yamaguchi, S., Imai, A. and Iguchi, Y. (1994) Microstructure and Crystallization Behaviour of $\mathrm{TiO}_{2}$ Precursor Prepared by the Sol-Gel Method Using Metal Alkoxide. Journal of Materials Science, 29, 1617-1622. http://dx.doi.org/10.1007/BF00368935

[141] Sun, J., Gao, L. and Zhang, Q. (2003) Synthesizing and Comparing the Photocatalytic Properties of High Surface Area Rutile and Anatase Titania Nanoparticles. Journal of the American Ceramic Society, 86, 1677-1682. http://dx.doi.org/10.1111/j.1151-2916.2003.tb03539.x

[142] Zhang, Q., Gao, L. and Guo, J. (2000) Effects of Calcination on the Photocatalytic Properties of $\mathrm{Nanosized} \mathrm{TiO}_{2}$ Powders Prepared by $\mathrm{TiCl}_{4}$ Hydrolysis. Applied Catalysis B: Environmental, 26, 207-215. http://dx.doi.org/10.1016/S0926-3373(00)00122-3

[143] Chen, J., Gao, L., Huang, J. and Yan, D. (1996) Preparation of Nanosized Titania Powder via the Controlled Hydrolysis of Titanium Alkoxide. Journal of Materials Science, 31, 3497-3500.

[144] Banfield, J. (1998) Thermodynamic Analysis of Phase Stability of Nanocrystalline Titania. Journal of Materials Chemistry, 8, 2073-2076. http://dx.doi.org/10.1039/a802619j

[145] Yanagisawa, K. and Ovenstone, J. (1999) Crystallization of Anatase from Amorphous Titania Using the Hydrothermal Technique: Effects of Starting Material and Temperature. The Journal of Physical Chemistry B, 103, 7781-7787. http://dx.doi.org/10.1021/jp990521c

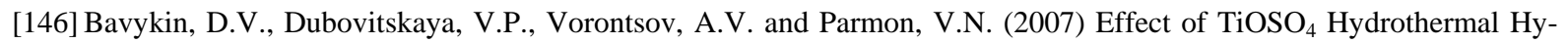
drolysis Conditions on $\mathrm{TiO}_{2}$ Morphology and Gas-Phase Oxidative Activity. Research on Chemical Intermediates, 33, 449-464. http://dx.doi.org/10.1163/156856707779238702

[147] Wang, C.C. and Ying, J.Y. (1999) Sol-Gel Synthesis and Hydrothermal Processing of Anatase and Rutile Titania Nanocrystals. Chemistry of Materials, 11, 3113-3120. http://dx.doi.org/10.1021/cm990180f

[148] Penn, R.L. and Banfield, J.F. (1999) Morphology Development and Crystal Growth in Nanocrystalline Aggregates under Hydrothermal Conditions: Insights from Titania. Geochimica et Cosmochimica Acta, 63, 1549-1557. http://dx.doi.org/10.1016/S0016-7037(99)00037-X

[149] Zhang, H. and Banfield, J.F. (2002) Kinetics of Crystallization and Crystal Growth of Nanocrystalline Anatase in Nanometer-Sized Amorphous Titania. Chemistry of Materials, 14, 4145-4154. http://dx.doi.org/10.1021/cm020072k

[150] Kumar, S.R., Suresh, C., Vasudevan, A.K., Suja, N.R., Mukundan, P. and Warrier, K.G.K. (1999) Phase Transformation in Sol-Gel Titania Containing Silica. Materials Letters, 38, 161-166. http://dx.doi.org/10.1016/S0167-577X(98)00152-9

[151] Zhang, J., Hu, Y., Matsuoka, M., Yamashita, H., Minagawa, M., Hidaka, H. and Anpo, M. (2001) Relationship between the Local Structures of Titanium Oxide Photocatalysts and Their Reactivities in the Decomposition of NO. The Journal of Physical Chemistry B, 105, 8395-8398. http://dx.doi.org/10.1021/jp012080e

[152] Yoneyama, H., Haga, S. and Yamanaka, S. (1989) Photocatalytic Activities of Microcrystalline Titania Incorporated in Sheet Silicates of Clay. The Journal of Physical Chemistry, 93, 4833-4837. http://dx.doi.org/10.1021/j100349a031

[153] Caillol, S. (2011) Fighting Global Warming: The Potential of Photocatalysis against $\mathrm{CO}_{2}, \mathrm{CH}_{4}, \mathrm{~N}_{2} \mathrm{O}$, CFCs, Tropospheric $\mathrm{O}_{3}$, BC and Other Major Contributors to Climate Change. Journal of Photochemistry and Photobiology C: Photochemistry Reviews, 12, 1-19. http://dx.doi.org/10.1016/j.jphotochemrev.2011.05.002

[154] Tanabe, K., Sumiyoshi, T., Shibata, K., Kiyoura, T. and Kitagawa, J. (1974) A New Hypothesis Regarding the Surface Acidity of Binary Metal Oxides. Bulletin of the Chemical Society of Japan, 47, 1064-1066. http://dx.doi.org/10.1246/bcsj.47.1064 